\title{
Gas cooking is associated with small reductions in lung function in children
}

\author{
H. Moshammer*, T. Fletcher" ${ }^{\#}$ J. Heinrich", G. Hoek ${ }^{+}$, F. Hruba ${ }^{\S}$, S. Pattenden\#, \\ P. Rudnai ${ }^{f}$, H. Slachtova**, F.E. Speizer ${ }^{\# \#}$, R. Zlotkowska ${ }^{\text {"ศ }}$ and M. Neuberger*
}

ABSTRACT: Inconsistent effects of gas cooking on lung function have been reported. In a previous study from Austria, we demonstrated a significant, though small, reduction of lung function parameters in children living in homes with gas stoves. We used a larger international database to check if this finding can be generalised.

To study the relative impact of cooking with gas on lung function parameters of primary school children in a wide range of geographical settings, we analysed flow and volume data of $\sim 24,000$ children (aged 6-12 yrs) from nine countries in Europe and North America.

Exposure information was obtained by comparable questionnaires and spirometry according to an American Thoracic Society/European Respiratory Society protocol. Linear regressions were used, controlling for individual risk factors and study area. Heterogeneity between study-specific results and mean effects were estimated using meta-analytical tools.

On average, gas cooking reduced lung function parameters. Overall effects were small (-0.1$0.7 \%$ ) and only significant for forced vital capacity and forced expiratory volume in $1 \mathrm{~s}$. There was some indication that allergic children were more affected by gas cooking.

Under current housing conditions, gas cooking is associated with only small reductions in lung function.

KEYWORDS: Indoor pollutants, nitrogen dioxide, respiratory health, spirometry

$\mathrm{U}$ ntil now, findings on lung function effects of gas cooking are still controversial. While BERKEY et al. [1] and WARE et al. [2] mostly showed no effect, others [3-5] found a reduced lung function notably mostly in girls. PONSONBY and colleagues $[6,7]$ reported stronger effects in sensitised children. Several studies found reduced respiratory health mostly measured by reported symptoms associated with gas stoves [8-13].

We recently published a study from Linz, Austria, in which spirometric lung function parameters were reduced in children from households with gas stoves by $1.1-3.4 \%$ [14]. The data from Austria were part of the "Pollution and the Young" (PATY) project, a large data-pooling study on indoor and outdoor environmental factors on the respiratory health of children. In the framework of the PATY project, we published on the health impact of smoking in pregnancy and current passive smoking on the lung function of school children [15], indoor moulds [16] and socioeconomic status [17]. The results from Austria on gas cooking triggered interest in the effects of gas cooking in the larger dataset from all nine countries. The aims of the current study were to evaluate the associations between gas cooking and lung function in a large population of children $(\sim 24,000)$ and to assess whether this association depends on sex and atopic status.

\section{METHODS}

Details of the PATY study have been described before [15]. Briefly, the analysis pooled data of 24,000 children (aged 6-12 yrs) from nine countries in Europe (Austria, Germany, the Netherlands, Poland, Hungary, the Czech Republic and Slovakia) and North America (USA and Canada). Lung function testing was performed according to the protocol of the American Thoracic Society [18], except for minimum exhalation time of $6 \mathrm{~s}$ (not feasible for children) and except for the Dutch study which followed the protocol of European Respiratory Society [19]. Prediction formulae were developed for each country separately, according to the same regression model. Because lung growth in the time period of interest was not linear, the lung function variables were log-transformed. Log(age), $\log ($ weight $)$ and $\operatorname{sex} \times \log$ (height) were included in all calculations as the most important predictors for the log lung function variables $[14,15,20,21]$. With this model, the exponentials

\section{AFFILIATIONS}

${ }^{*}$ Medical University of Vienna, Inst. Env. Health, Vienna, Austria. \#London School of Hygiene and Tropical Medicine, London, UK. - German Research Center for Environmental Health, Institute for Epidemiology, Munich, Germany. +Institute for Risk Assessment Sciences, Utrecht University, Utrecht The Netherlands.

${ }^{\S}$ Dept of Health Statistics and Informatics, Regional Authority of Public Health, Banska Bystrica, Slovakia.

${ }^{f}$ National Institute of Environmental Health, Budapest, Hungary.

**Institute of Public Health, Ostrava, Czech Republic.

\#\#Harvard School of Public Health, Boston, MA, USA.

"Dept of Environmental Health and Epidemiology, Institute of Occupational Medicine and Environmental Health, Sosnowiec, Poland

CORRESPONDENCE

H. Moshammer Inst. Environmental Health Kinderspitalgasse 15 1095 Vienna Austria E-mail: hanns.moshammer@ meduniwien.ac.at

Received: Jan 302009 Accepted after revision: Nov 272009 First published online: Jan 042010 
of the effect estimates of exposure can easily be interpreted as percentage differences.

Study results are presented for the "basic model", adjusted for age, weight, height, sex, seasonal trends (by adding a dummy for the four seasons), technician and/or instrument (if the study centre used more than one) and study area (as a random effect), and for the "adjusted model", additionally adjusted for potential confounders, namely smoking in pregnancy (that was found to be the strongest "smoking" predictor of lung function by MOSHAMMER et al. [15]), recent respiratory infections, current medication, maximal parental education, household crowding, unventilated gas/oil/kerosene heater, mould, birth order, and "ever had a pet". These study-specific effect estimates and their confidence intervals were entered into a meta-analysis, from which forest plots of the estimates, a mean estimate and a measure and Cochran Chi-squared test of between-study heterogeneity were obtained. The study-specific estimates were assumed to follow a random distribution about a mean and the estimation of this mean and its confidence interval takes into account both the variation in study-specific estimates and the uncertainty (due to sampling variability) related to each study-specific estimate [22].

\section{RESULTS}

Of the 24,019 respondents included in the study, 9,783 (40.73\%) reported cooking with gas, while in the households of 13,887 $(57.82 \%)$ children solely electric stoves were used (table 1). For 349 children, information on cooking was missing. Averaged over all study centres cooking with and without gas was fairly evenly distributed. However, while a high percentage of households from the Central European Study of Air Pollution and Respiratory Health (CESAR) centres (Poland, Hungary, the Czech Republic and Slovakia [23]) and from the Netherlands cooked with gas, this was only true for a minority from North America and Austria. The German households displayed a more balanced distribution.

In the basic model, gas stoves reduced all lung function parameters between $0.1 \%$ (maximal expiratory flow at $25 \%$ of forced vital capacity (MEF25\%)) and $0.8 \%$ (peak expiratory flow $(\mathrm{PEF})$ ). This reduction was significant for forced expiratory volume in $1 \mathrm{~s}$ (FEV1) (0.7\%) and forced vital capacity (FVC) $(0.6 \%)$, only. There was limited indication for heterogeneity between study centres for PEF and MEF75\% ( $p$ for heterogeneity: 0.062 and 0.097 , table 2, fig. 1). For the other parameters, no indication for heterogeneity was found. After adjusting for recent respiratory infections, current smoking exposure, smoking during pregnancy, maximal parental education, mould, pet ownership, season and geographical area (adjusted model), the effect estimates did not change much. Effect estimates remained small and mostly insignificant (table 2).

In a restricted data set without the Austrian results, the effects on FVC and FEV1 remained significant. After the elimination of the Austrian data there was no longer any hint of heterogeneity. Exclusion of the dataset from North America as the largest, instead of the Austrian data, did not lead to substantial changes in the effect estimates.

There was no statistically significant difference in the effect estimates when stratified by sex. For males, the effect estimates for FVC and FEV1 were $0.6 \%(95 \%$ CI $-0.1-1.3)$ and $0.6 \%(95 \%$

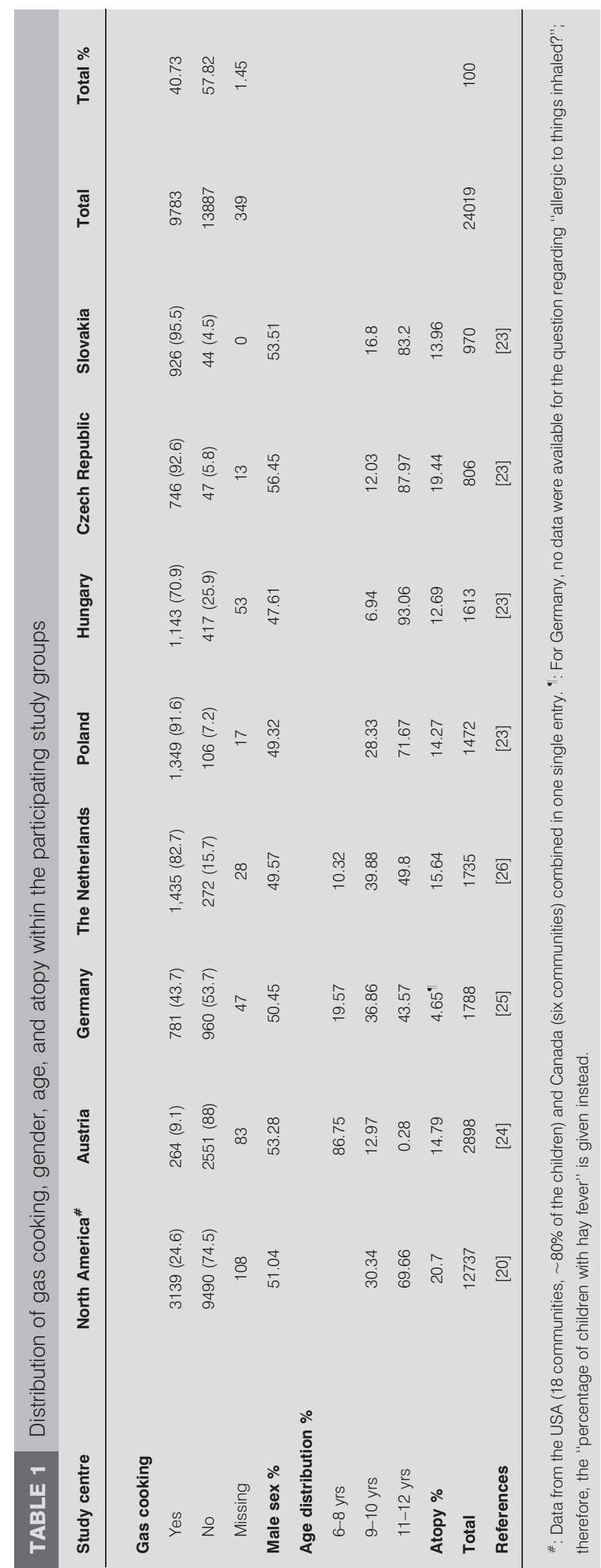


TABLE 2 Relative change (reduction in \% and 95\% Cl) of the expected lung function outcome due to cooking with gas

\begin{tabular}{|c|c|c|c|c|}
\hline & \multicolumn{3}{|c|}{ Basic model } & \multirow[t]{2}{*}{ Adjusted model } \\
\hline & All datasets & Excluding Austria & Excluding North America & \\
\hline FVC & $0.6(0.2-1.1)$ & $0.5(0.1-0.8)$ & $0.8(0.1-1.5)$ & $0.5(0.0-1.1)$ \\
\hline p-heterogeneity & 0.304 & 0.4016 & 0.255 & 0.216 \\
\hline FEV 1 & $0.7(0.1-1.2)$ & $0.5(0.1-0.8)$ & $0.9(0.1-1.6)$ & $0.5(-0.1-1.2)$ \\
\hline p-heterogeneity & 0.062 & 0. 188 & 0.077 & 0.100 \\
\hline MMEF & $0.4(-0.7-1.4)$ & $0.1(-0.9-1.1)$ & $1.0(-0.6-2.6)$ & $0.1(-1.0-1.3)$ \\
\hline p-heterogeneity & 0.396 & 0.570 & 0.41 & 0.368 \\
\hline MEF25\% & $0.1(-1.2-1.5)$ & $-0.1(-1.5-1.2)$ & $1.2(-0.9-3.2)$ & $-0.1(-1.5-1.3)$ \\
\hline p-heterogeneity & 0.411 & 0.436 & 0.514 & 0.412 \\
\hline MEF50\% & $0.7(-0.3-1.7)$ & $0.4(-0.6-1.5)$ & $0.8(-1.0-2.6)$ & $0.3(-0.7-1.4)$ \\
\hline
\end{tabular}

CI -0.1-1.4), respectively. For females, the corresponding estimates were: $0.8 \%(-0.2-1.8)$ and $0.9 \%(-0.1-1.9)$, respectively. The p-values for interaction were 0.96 and 0.89 , respectively. For most of the other lung function parameters, stronger (although still insignificant) effects were found in males.

Stratifying by atopic status indicated stronger effects regarding all lung function parameters in children "allergic to things inhaled" (fig. 2). This question was not included in the German questionnaire; therefore, in this dataset, the question on hay fever was used instead. Inclusion and exclusion of the German dataset gave fairly similar results, as did the basic and the adjusted model. There was no indication of heterogeneity (all p-values were much larger than 0.1) nor were there differences in the point estimates between fixed and random model. Figure 2 depicts the basic model, including the German data with fixed estimates. Also, interaction (atopy $\times$ gas cooking) was studied and the p-value of the interaction factor (again basic model, including German data set and fixed estimates) is indicated in figure 2.

Additionally, similar models were run to look for effects of reported moulds, household crowding and heating device (the confounders in the adjusted model) but no consistent effects were found. The effect of smoking was reported in a separate paper [15].

\section{DISCUSSION}

Several studies found reduced respiratory health associated with gas stoves [3-13]. $\mathrm{NO}_{2}$ emitted from gas stoves and ovens can increase exposure, especially in small kitchens with tight windows, to concentrations above the threshold limit value (protecting workers) and well above ambient air quality standards (protecting the general public). As an irritant gas poorly soluble in water, $\mathrm{NO}_{2}$ reaches the peripheral airways and causes small airway dysfunction [27]. Other irritant gases emitted during burning of natural gas, such as formaldehyde, are water soluble and, therefore, affect the upper airways. Additionally, (ultra-)fine particulate matter might be involved in lung function impairments. Fine particulates from cooking are not associated with gas cooking in particular, but with all heating of foods. Thus $\mathrm{NO}_{2}$ and/or other unmeasured components from gas use could lead to inflammatory responses in the airways [28]. PEF and MEF75\% indicate large airway dysfunction, but the variability is caused by effort and muscle strength. MEF50\% and MEF25\% are less effort dependent but their reproducibility depends on the completeness of expiration. MEF25\% would be the best indicator for small airway dysfunction if reproducible.

This international pooled dataset does not strongly support the comparatively strong findings from Austria [14]. There was only limited evidence of heterogeneity in effect estimates between centres. But even upon removal of the Austrian data (which had the strongest effects but had only little weight in the overall estimate because of the low number of exposed children) point estimates remained consistent (small reduction in all lung function parameters with gas cooking, significantly so for FVC and FEV1).

Infrastructure for gas supply differs between cities and also within cities, and other factors that could eventually influence lung function might also vary spatially. For example, the gas distribution system in some countries is restricted to the densely populated areas that likely also differ by outdoor air pollution and socioeconomic status. Although we controlled for socioeconomic status by means of parents' education, which did not alter the effect estimates, 
a)

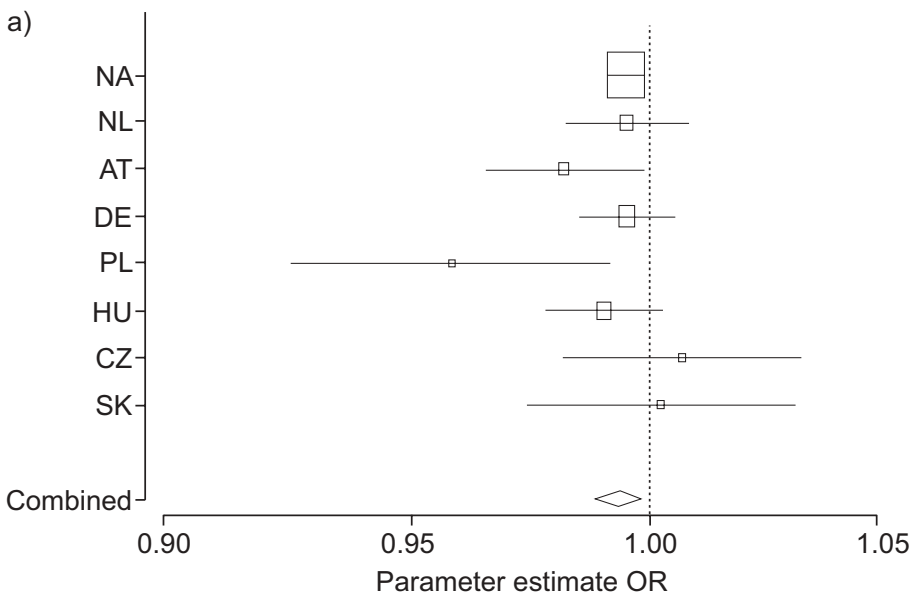

c)

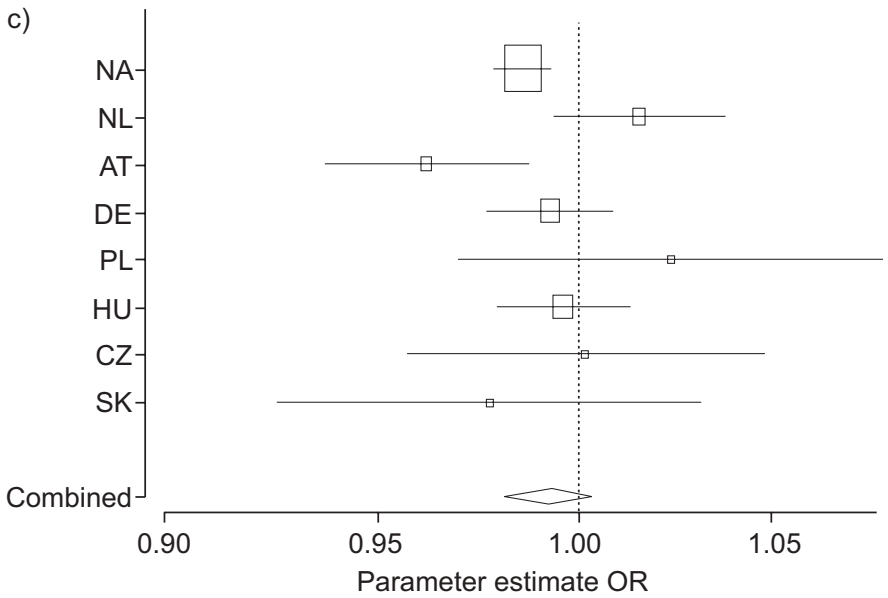

e)

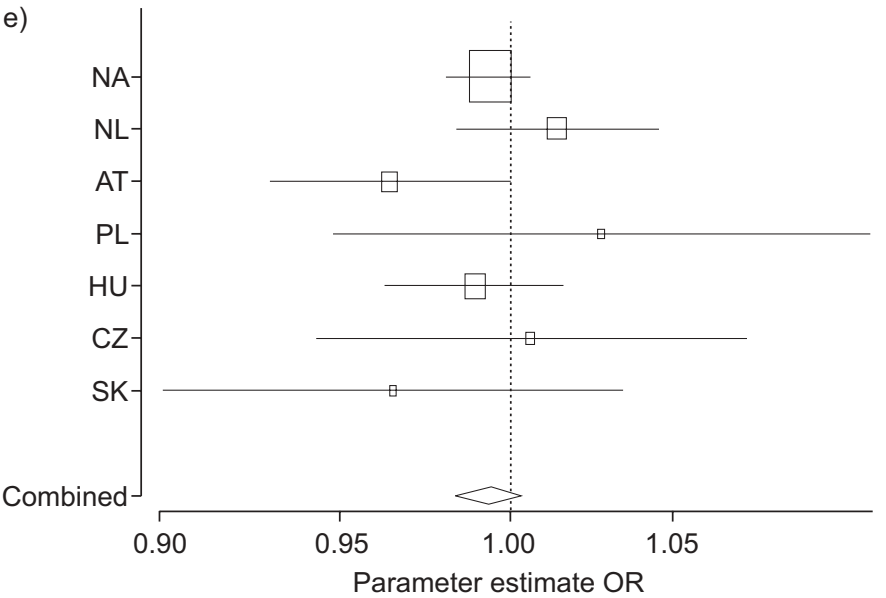

b)

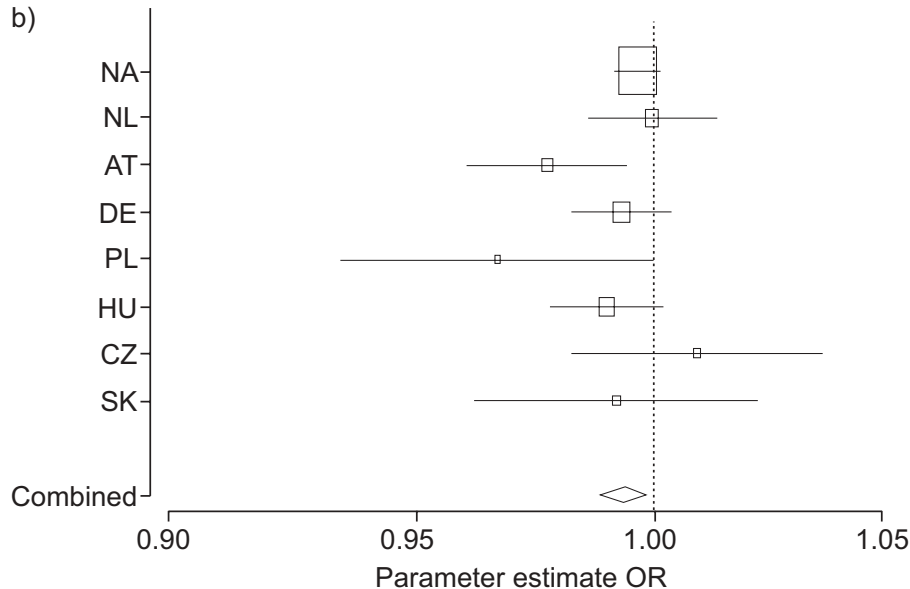

d)

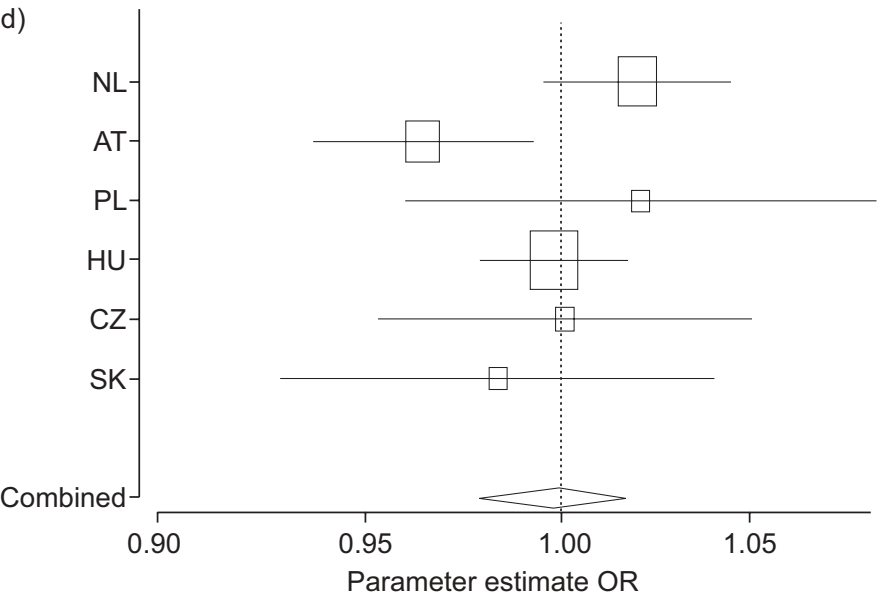

f)

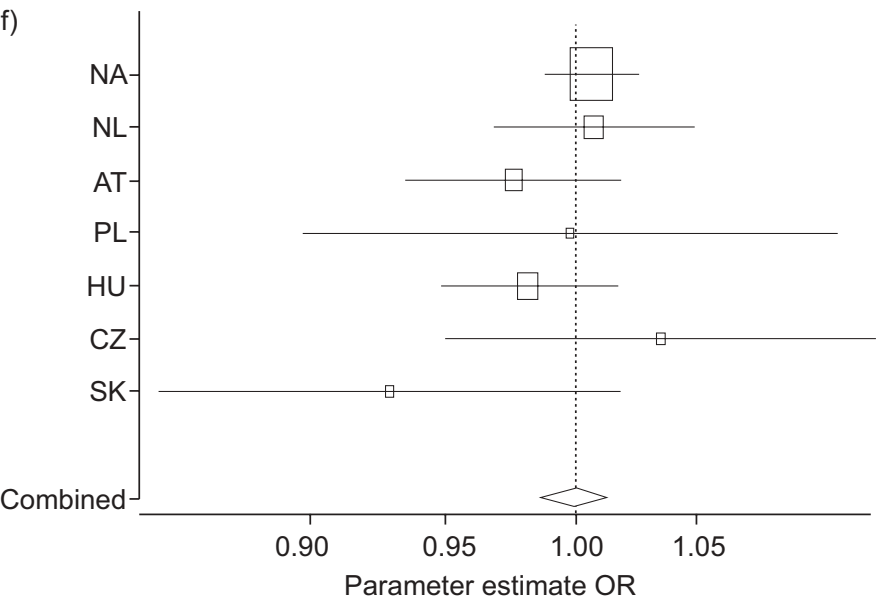

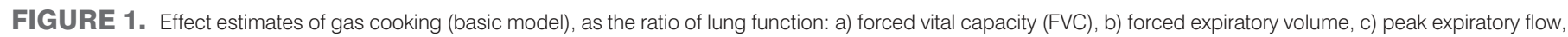

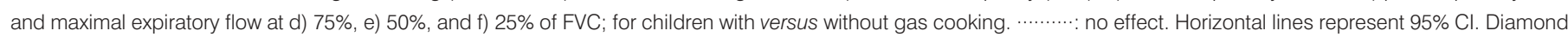

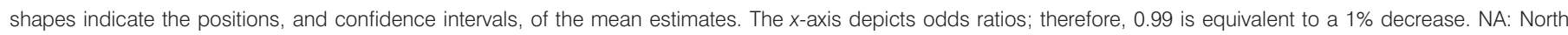
America, NL: the Netherlands, AT: Austria, DE: Germany, PL: Poland, HU: Hungary, CZ: Czech Republic, SK: Slovakia.

this proxy for socioeconomic status might not have been sufficient. Outdoor air pollution from central fixed monitors would have been too crude a measure of spatial differences and thus was not included in the analysis. Study area was included as a random effect even in the basic model. But a "very basic" model (simple linear model without random effects, data not shown) gave practically the same effect estimates. Therefore, neither residual confounding by area effects nor over-adjustment by the random effect model seems likely. 


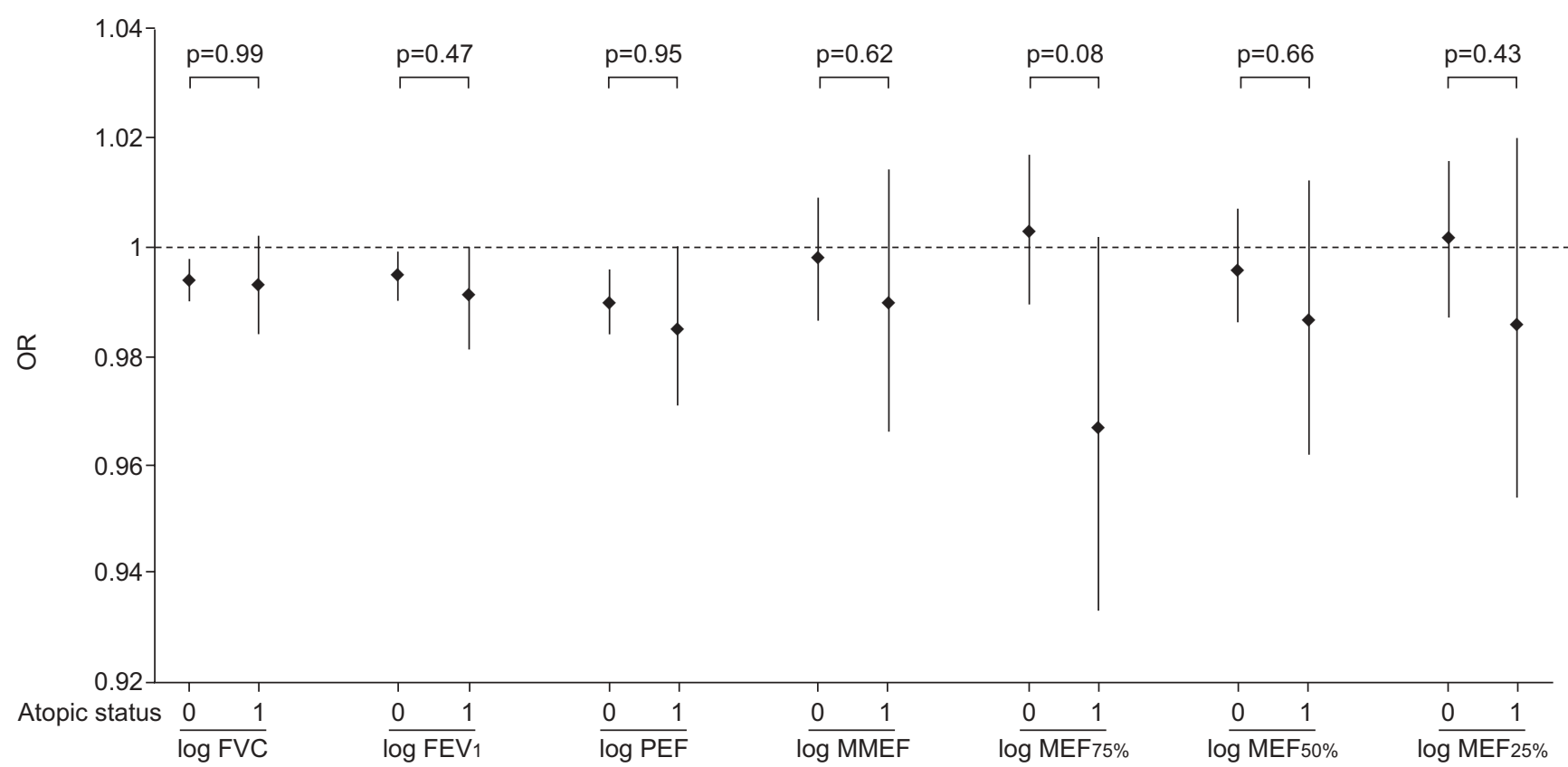

FIGURE 2. Effect estimates of gas cooking as the ratio of lung function for children with versus without gas cooking (basic model). Mean pooled estimates stratified by atopic status (allergic to things inhaled: $1=$ "yes"; $0=$ "no"). The $y$-axis depicts odds ratios; therefore, 0.99 is equivalent to a $1 \%$ decrease. The p-values for interaction are shown. FVC: forced vital capacity; FEV1: forced expiratory volume in 1 s; PEF: peak expiratory flow; MMEF: maximum mid-expiratory flow; MEFx\%: maximal expiratory flow at $\mathrm{x} \%$ of FVC.

The gas source in most of the participating centres during the time of the study was natural gas only. Measurements showed that gas stoves and ovens were the main source of $\mathrm{NO}_{2}$, and not gas furnaces, because most households at the time of the study used remote heating already. Ventilation was partly missing and partly unused (extractor hoods over stoves).

Cooking with gas can lead to substantially different exposures of children. Indeed, size of the kitchen, ventilation rate, intensity and duration of cooking and the time children spent at home, especially in the kitchen when cooking is going on, would all have a major influence on individual exposure. But information on these factors was missing. Only information about the current home environment was available. It is conceivable that mobility differed between study centres leading to different percentages of children who did not live in the same home in former years. If indeed early life exposure is more important for lung function development [15], this would lead to an unknown amount of exposure misclassification. On the other hand, MORAN et al. [29] found no persistent effect of childhood exposure to gas cooking but reduced lung function in young adults with current exposure.

This is not the only study finding no strong evidence of gas cooking having an impact on lung function $[8,30]$. CORBO et al. [4] reported an effect of gas cooking only in females with high IgE. Even the early study from Vienna [13] that, in fact, triggered this investigation in the first place, found only an increase in symptoms (cough) but no effect on lung function. Two more recent Austrian studies [31, 32] also failed to demonstrate an impact of gas cooking on lung function. At least in Austria, the size of flats tend to increase and children do spend less time in the kitchen with their parent cooking. In former days, children played or even did their homework in the kitchen where their mother/father could supervise them.

Contrary to others [3-5], we observed no consistent differences in the point estimates between girls and boys. Maybe these differences were caused mostly by sex-specific behaviours (female children spending more time at home and/or in the kitchen) and these behavioural differences might no longer be true. We did find some evidence that atopic children displayed a stronger effect from gas cooking as reported before $[4,6,7]$ although the number of atopic children exposed to gas cooking was rather small. It is evident that interaction is not significant for any single lung function parameter. In spite of the fact that in all lung function parameters, the effects of gas cooking is stronger in atopic children, the confidence intervals of the effect of gas cooking are always much broader for the atopic children. This is mostly due to the fact that there are fewer atopic children. So, at least in those countries with very unbalanced distribution between gas and electric cooking, there is only limited power to detect any effect in atopic children. Nevertheless, when children with respiratory allergies are living in "gas cooking" households, care should be taken of sufficient ventilation during cooking especially when the children are present in the kitchen.

\section{Conclusion}

The current study indicates that under current conditions, cooking with gas results in a small reduction of lung function, at least in the volume parameters (FVC and FEV1).

\section{STATEMENT OF INTEREST}

None declared. 


\section{ACKNOWLEDGEMENTS}

We are indebted to all scientists and technical staff involved in the planning and conduction of the studies, and to the children, parents and teachers for their cooperation. The PATY study was funded by the EU 5th Framework Quality of Life Program (proposal no. QLRT-2001-02544).

\section{REFERENCES}

1 Berkey CS, Ware JH, Dockery DW, et al. Indoor air pollution and pulmonary function growth in preadolescent children. Am J Epidemiol 1986; 123: 250-260.

2 Ware JH, Dockery DW, Spiro A 3rd, et al. Passive smoking, gas cooking, and respiratory health of children living in six cities. Am Rev Respir Dis 1984; 129: 366-374.

3 Chapman RS, Hadden WC, Perlin SA. Influences of asthma and household environment on lung function in children and adolescents: the third national health and nutrition examination survey. Am J Epidemiol 2003; 158: 175-189.

4 Corbo GM, Forastiere F, Agabiti N, et al. Effect of gas cooking on lung function in adolescents: modifying role of sex and immunoglobulin E. Thorax 2001; 56: 536-540.

5 Cuijpers CE, Swaen GM, Wesseling G, et al. Adverse effects of the indoor environment on respiratory health in primary school children. Environ Res 1995; 68: 11-23.

6 Ponsonby AL, Dwyer T, Kemp A, et al. A prospective study of the association between home gas appliance use during infancy and subsequent dust mite sensitization and lung function in childhood. Clin Exp Allergy 2001; 31: 1544-1552.

7 Ponsonby AL, Couper D, Dwyer T, et al. The relation between infant indoor environment and subsequent asthma. Epidemiology 2000; 11: 128-135.

8 Willers SM, Brunekreef B, Oldenwening M, et al. Gas cooking, kitchen ventilation, and asthma, allergic symptoms and sensitization in young children-the PIAMA study. Allergy 2006; 61: 563-568.

9 de Bilderling G, Chauhan AJ, Jeffs JAR, et al. Gas cooking and smoking habits and the risk of childhood and adolescent wheeze. Am J Epidemiol 2005; 162: 513-522.

10 Behrens T, Maziak W, Weiland SK, et al. Symptoms of asthma and the home environment. The ISAAC I and III cross-sectional surveys in Münster, Germany. Int Arch Allergy Immunol 2005; 137: 53-61.

11 Hölscher B, Heinrich J, Jacob B, et al. Gas cooking, respiratory health and white blood cell counts in children. Int J Hyg Environ Health 2000; 203: 29-37.

12 Volkmer RE, Ruffin RE, Wigg NR, et al. The prevalence of respiratory symptoms in South Australian preschool children. II. Factors associated with indoor air quality. J Paediatr Child Health 1995; 31: 116-120.

13 Neuberger M, Klima H, Rutkowski A, et al. Luftverunreinigung, Kochen, Heizen, Passivrauchen und respiratorische Symptomatik. Mitteilungen der österreichischen Sanitätsverwaltung 1986; 87: 363-366.

14 Moshammer H, Hutter HP, Neuberger M. Gas cooking and reduced lung function in school children. Atmos Environ 2006; 40: 3349-3354.
15 Moshammer H, Hoek G, Luttmann-Gibson H, et al. Parental smoking and lung function in children. An international study. Am J Respir Crit Care Med 2006; 173: 1255-1263.

16 Antova T, Pattenden S, Brunekreef B, et al. Exposure to indoor mould and children's respiratory health in the PATY study. J Epidemiol Community Health 2008; 62: 708-714.

17 Gehring U, Pattenden S, Slachtova H, et al. Parental education and children's respiratory and allergic symptoms in the PATY study. Eur Respir J 2006; 27: 95-107.

18 American Thoracic Society. Standardization of spirometry-1987 update. Am Rev Respir Dis 1987; 136: 1286-1298.

19 European Respiratory Society. Standardized lung function testing Official statement of the European Respiratory Society. Eur Respir J 1993; 5: Suppl. 15, 1-100.

20 Raizenne M, Neas LM, Damakosh AI, et al. Health effects of acid aerosols on North American children: pulmonary function. Environ Health Perspect 1996; 104: 506-514.

21 Zapletal A, Motoyama EK, Van De Woestijne KP, et al. Maximum expiratory flow-volume curves and airway conductance in children and adolescents. J Appl Physiol 1969; 26: 308-316.

22 Der Simonian R, Laird N. Meta-analysis in clinical trials. Control Clin. Trials 1986; 7: 177-188.

23 Leonardi GS, Houthuijs D, Nikiforov B, et al. Respiratory symptoms, bronchitis and asthma in children of Central and Eastern Europe. Eur Respir J 2002; 20: 890-898.

24 Neuberger M, Moshammer H, Kundi M. Declining ambient air pollution and lung function improvement in Austrian children. Atmospheric Environment 2002; 36: 1733-1736.

25 Heinrich J, Hoelscher B, Wjst M, et al. Respiratory diseases and allergies in two polluted areas in East Germany. Environ Health Perspect 1999; 107: 53-62.

26 Janssen NA, Brunekreef B, van Vliet P, et al. The relationship between air pollution from heavy traffic and allergic sensitization, bronchial hyperresponsiveness, and respiratory symptoms in Dutch schoolchildren. Environ Health Perspect 2003; 111: 1512-1518.

27 Neuberger M, Kundi M, Haider M. Combined effects of outdoor and indoor air pollution on lung functions of school children. Arch Complex Environ Studies 1995; 7: 7-11.

28 Hölscher B, Heinrich J, Jacob B, et al. Gas cooking, respiratory health and white blood cell counts in children. Int J Hyg Environ Health 2000; 203: 29-37.

29 Moran SE, Strachan DP, Johnston ID, et al. Effects of exposure to gas cooking in childhood and adulthood on respiratory symptoms, allergic sensitization and lung function in young British adults. Clin Exp Allergy 1999; 29: 1033-1041.

30 Eisner MD, Blanc PD. Gas stove use and respiratory health among adults with asthma in NHANES III. Occup Environ Med 2003; 60: 759-764.

31 Hutter HP, Borsoi L, Moshammer H, et al. Assessing lung function and respiratory health in schoolchildren as a means to improve local environmental condition. J Public Health Policy 2009; 30: 144-157.

32 Hohenblum P, Fröhlich M, Moosmann L, et al. LUKI - LUft und Kinder. Einfluss der Innenraumluft auf die Gesundheit von Kindern in Ganztagsschulen. Endbericht. Umweltbundesamt. Vienna. www. umweltbundesamt.at/fileadmin/site/publikationen/REP0182.pdf Date last accessed: June 22, 2009. 